\title{
Study on the VEGF Gene Expression and the Role of PMSG Hormone in the Development of Endometrial Cancer in Mice
}

\author{
Sang-Hwan $\mathrm{Kim}^{1}$, Na-Hyeon Jung ${ }^{2}$, Min-Gee $\mathrm{Oh}^{3}$ and Jong-Taek Yoon ${ }^{1,3, *}$ \\ ${ }^{1}$ Institute of Genetic Engineering, Hankyong National University, Anseong 17579, Korea \\ ${ }^{2}$ Major in the Animal Biotechnology, Graduate School of Future Convergence Technology, Hankyong National \\ University, Anseong 17579, Korea \\ ${ }^{3}$ Department of Animal Life Science, Hankyong National University, Anseong 17579, Korea
}

Received March 7, 2020

Revised March 14, 2020

Accepted March 16, 2020

*Correspondence

Jong-Taek Yoon

E-mail: jtyoon@hknu.ac.kr

ORCID

https://orcid.org/0000-0002-9408-8239
ABSTRACT In this study, we investigated whether infusion of colorectal cancer cell line and PMSG could increase endometrial cancer. As a result, our study confirmed that the injection of colorectal cancer can cause inflammation and cancer in the uterus and increase the VEGF gene in the uterus. The study also found that endometrial cancer was associated with PMSG.

Keywords: colorectal cancer cell, endometrium cancer, mouse, uterus, VEGF

\section{INTRODUCTION}

Endometrial cancer (EC) which forms in the endometrium, accounts for $4.8 \%$ of all cancers worldwide and is classified as the most common cancer in developed countries. In particular, endometrial cancer may be caused by endometrial inflammation occurring during menstrual periods, and a problem may be formed due to an error in physiological hormone mechanisms. Approximately $75 \%$ of all ECs are diagnosed as FIGO (International Federation of Gynecology and Obstetrics). Stage I or II, with a fiveyear overall survival rate of between $74 \%$ and $91 \%$. Patients diagnosed with FIGO phase III or IV have a 5-year overall survival rate of $57-65 \%$ and $20-26 \%$ respectively (Ferlay et al., 2015; Torre et al., 2015). The causes of ECs disease are high levels of estrogen, diabetes, obesity and menopause (Siegel et al., 2015; Morice et al., 2016). Therefore, the development of a model for the study of endometrial cancer plays an important role for treatment of chemotherapy and physiological remodeling in tissue. The study of endometrial cancer is mainly studied using cell lines, but there are many experimental limitations, and it is insufficient to study the occurrence of cancer and tissue modification in vivo (Glaab et al., 1998; Weigelt et al., 2013). In the case of endometrial cancer, several different cell lines have been established during the past few decades. The most commonly used cell lines (AN3CA, ECC-1, HEC1A, HEC1B, and Ishikawa) are type I tumorderived cell lines, harboring alterations in the PI3K/Akt pathway, thereby representing the majority of EC tumors (Cheung et al., 2011; McConechy et al., 2012). However, in the physiological state, many cell deformations are formed, and it is easy to study only the formation part of the tumor, and it is insufficient to study the cause of direct and indirect metastasis of cancer and deformation of endometrial cells (Kim and Choi, 2009; Lee and Song, 2013; Lin et al., 2017). Many studies have used models of endometrial cancer utilizing cancer cell-lines derived 
from the human endometrium. However, for cancer incidence, the analysis of the cause by metastasis of cancer is more important than the direct cause. Especially, metastasis of cancer between organs in colorectal cancer (CRC) is associated with a poor prognosis and reduces the long term survival of patients (Siegel et al., 2017). There are about 500,000 cases of liver metastasis from CRC annually in world and until recently, its incidence was still very high (Lionti et al., 2018). And so, the present study confirmed whether Human colorectal cancer cell line (HCT116: ATCC (Manassas, VA, USA)) (Arnold et al., 2005; Sillars-Hardebol et al., 2010), a human colon cancer cell line with high metastasis rate and physiologically high variability, causes intrauterine inflammation in mice when injected into the abdominal cavity. Also analysis was conducted on whether the increase in PMSG (Jin and Yang, 1997; Yun et al., 1998) in the body could increase the incidence of endometrial cancer.

\section{MATERIALS AND METHODS}

\section{Preparation and certification of animals}

Female ICR mice (Institute of Cancer Research) were obtained from Dahan Bio Link (Eumseong, Korea) and maintained in light-controlled and air-conditioned rooms. And animals were kept on a 12 hours dark/night schedule at a constant temperature of $21^{\circ} \mathrm{C}$ and at $50 \%$ relative humidity. All animal procedures followed the protocol approved by the Animal Experimentation Ethics Committee at Hankyong National University (permission number: 2018-1). All surgeries were performed under pentobarbital sodium anesthesia and every effort was made to minimize pain. All ovaries were treated to stimulate ovulation and then used in the experiment. Stimulation involved injecting 5 IU PMSG (Pregnant mare serum gonadotropin: Serotropin; Teikoku Zoki, Tokyo, Japan) into the abdominal cavity and injecting 5 IU HCG (Human chorionic gonadotropin: Puberogen $^{\oplus}$; Sankyo, Tokyo, Japan) 48 hours later (Lee et al., 2018).

\section{Animals and HCT116 cancer cell-line implantation procedure}

The uterus position of the left lower abdomen of the centerline was marked for injection (skin and muscles). And $1 \times 106$ of HCT116 cells resuspended in $50 \mu \mathrm{L}$ of sterile water for injection (BITDruginfo, SC, Kor) were inject- ed twice every seven days directly under the skin where the uterus is located. A $0.3 \mathrm{~mm}$ insulin syringe (Omnican 50, B-Braun, Melsungen, Germany) was used for the injection. After the injected the animals were placed in a warm environment and observed changes in the condition of body's. In addition, mice case of injected with both PMSG and cancer cell, PMSG was injected into the abdominal cavity every three days. After, all uterus were obtained from 18 mice at 9 weeks of age in experiment. Six female mice were randomly divided into three groups including: normal control group (NC), cancer injected group (PC: positive control group), and PMSG group (PP: PMSG + Cancer injected group). The mice of each group collected the uterus according to the method of dissection.

\section{Histological analysis of the endometrium}

After the end of hormone treatments, each group uterus were collected and fixed in 70\% Diethyl pyrocarbonate (DEPC)-ethanol, dehydrated, paraffin-embedded and sectioned at $5 \mathrm{um}$ thickness. After representative sections from each uterus paraffin-block in treatment group were randomly elect and routine hematoxylin and eosin (H\&E) staining and DAPI fluorescence (V11324, Thermo Fisher Scientific Solutions, Massachusetts, USA) staining was performed for histological inspection with optical microscope $(\times 40, \times 100, \times 400)$ (Kim et al., 2011; Kim et al., 2018).

\section{Immunofluorescence (IF)}

To perform immunofluorescence analysis, each uterus was fixed in 3\% formalin. After dehydration was induced, the tissue was made transparent using Potassium Hydroxide $(\mathrm{KOH})$ in multiple wells. After, the samples were blocked at RT (Room Temperature) for $1 \mathrm{~h}$ in TBS (1xPBS with $0.01 \%$ Triton X-100), containing 5\% normal horse serum (NHS), and induced antigen antibody reaction using primary antibodies (VEGF (ab2350, Abcam, Cambridge, UK): diluted 1:200 in blocking buffer) overnight at $4^{\circ} \mathrm{C}$. After, the samples were incubated with secondary antibodies (anti-Rabbit (ab6721, Abcam, Cambridge, UK): diluted 1:500 in blocking buffer) for $2 \mathrm{hr}$ at RT and then washed with PBS for $30 \mathrm{~min}$. The sample was finally dyed with DAPI and observed in the fluorescence microscope (Nikon Corp., Tokyo, Japan) at $\times 100$ and $\times 200$ magnification. 


\section{RESULTS}

\section{H\&E staining of mus uterus}

The histological changes of the endometrium between normal and cancer-injected groups are shown in Fig. 1. In the normal group, the borders and cell compartments of myometrium and endometrium of the endometrium were uniformly observed. However the density and homogeneity of the endometrial cells were low in the PC and PP groups. In particular, although PC and PP both had higher expansion of Lumen section compared to NC group, but fat cells were increased in Glandular cell area and connective tissue zone, and cell density was low. In addition, we observed densely packed little tumors in each section of the endometrium, and confirmed that the inflammation was increased in the epithelial tissue section. In particular, the uterus of the PP group had increased fat zones and cell detachment zones, and many inflammatory features were observed in the endometrium.

\section{Comparison of anatomical morphology and endometrium remodeling}

Anatomical observations are shown in Fig. 2 in normal and cancer groups. Compared with the normal group, fat deposition rate in the cancer mouse group was increased, and the small intestine, large intestine and liver were lowered below transverse diaphragm. Fat accumulation in the abdominal cavity was noticeably observed in the PC, and was observed in the PP in small quantities, but the dilation rate of the intestine was very high. In endometrial fluorescence analyzed result that the damage between the PC and PP Uterus gland was very high, the atrophy of the glandular area was increased, and the cell deformation of the stroma was increased. In particular, in the PP, the atrophy of the glandular area and the lumen were extended, and the density of the stroma was increased, and cellular elimination had been increased.
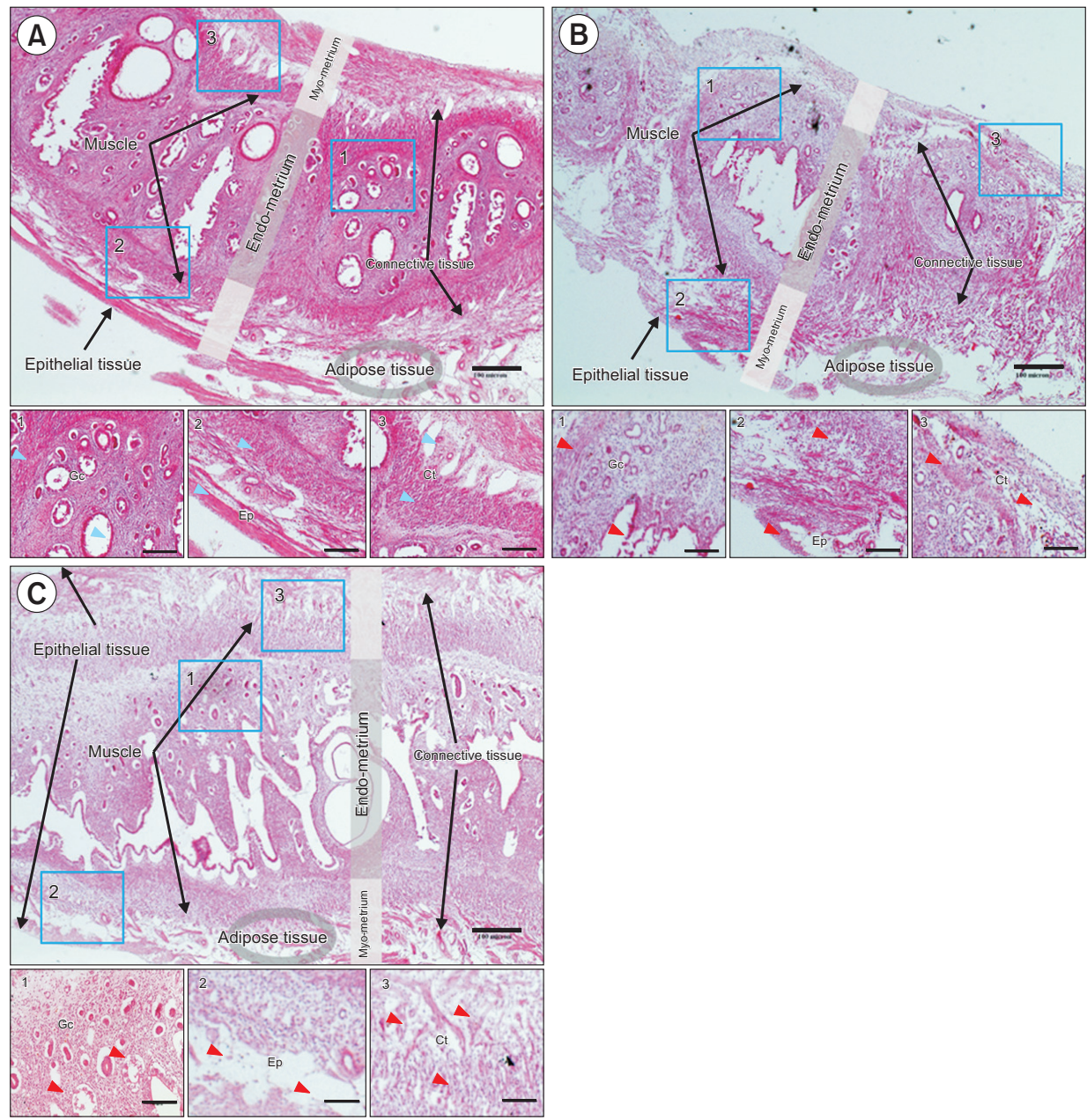

Fig. 1. Histological characterization of the orthotopic endometrial cancer model. Ep, epithelial tissue of endometrium; Gc, glandular cell area; Ct, connective tissue; $M$, myometrium. Blue arrow is normal condition zone, Red arrow is abnormality area. (A) Normal of uterus, (B) Uterus of mouse injected with cancer cell-line, (C) Uterus of mouse injected with cancer cell-line and PMSG hormone. 1: Endometrium, 2: Myometrium and primetrium, 3: Endometrium and myometrium (bar = $100 \mathrm{um})$. 

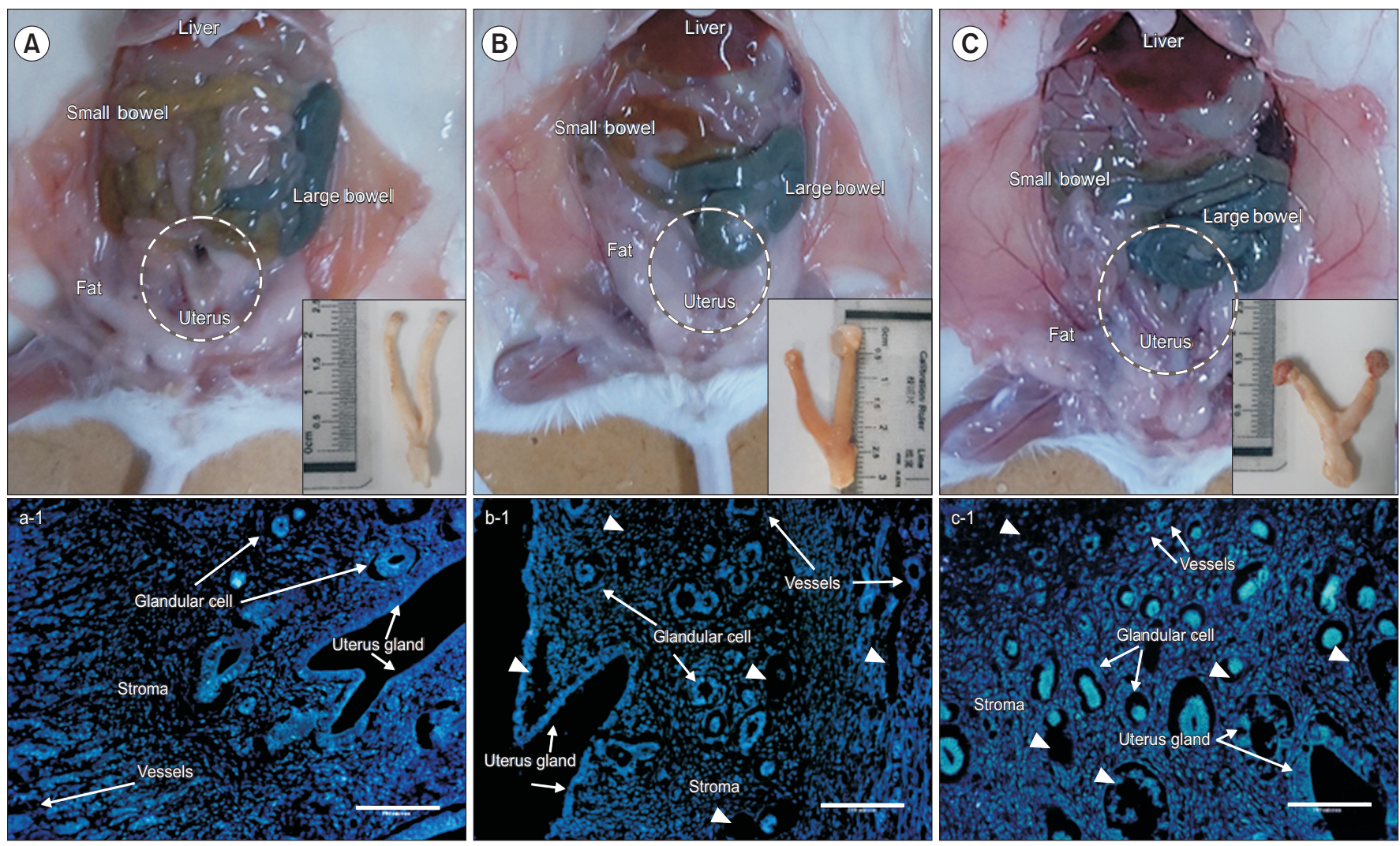

Fig. 2. Anatomical and cellular distribution analysis of each mouse. White arrows is indicate abnormal sections. (A) Normal of uterus, (B) Uterus of mouse injected with cancer cell-line, (C) Uterus of mouse injected with cancer cell-line and PMSG hormone. a-1-c-1: Endometrium (bar $=100 \mathrm{um}$ ).

\section{Analysis of VEGF protein expression in uterus of cancer cell-injected mice}

The results of analyzing tissue changes caused by cancer cell transfer through VEGF manifestation in the endometrial membrane are as shown in Fig. 3. VEGF protein manifestation in myometrium and perimetrium was expressed in all three groups, and in the normal group, the manifestation in myometrium section was shown, but in the case of PC and PP, the incidence in endometrium increased. The size of the endometrial membrane has also changed, as shown in the preceding results, the increase in endometrial membranes was gradually increasing from normal groups to PP, and especially physiological changes of uterus were observed in PP, where the expression of the VEGF gene was very high.

\section{DISCUSSION}

The occurrence of endometrial cancer is known worldwide as a common cancer that occurs after menopause in women or due to hormonal imbalances (Park and Kang, 2011; Ferlay et al., 2015; Torre et al., 2015). There are opinions that such a phenomenon can be caused by inflammation in the endometrium of the uterus, accompanied by physiological irregularity, and classified as cancer that can lead to death if serious (Siegel et al., 2015; Morice et al., 2016). Therefore, the development of a precise physiological mechanism of endometrial cancer and a model that can control cancer is very important for understanding the physiological mechanism in the body that cannot be analyzed only by cell-lines. In this study, we investigated whether cancer can spread to the endometrium by injecting HCT116 cancer cell-line into the lower abdominal uterus without using the endometrial cancer cell-line. The results of this study confirmed that tissue deformation was observed in the endometrial layer of the uterus three weeks after the cancer cell injection, and that internal membrane damage was increased. In particular, the increase in PMSG hormones that affect ovarian growth after the injection of cancer cells was 

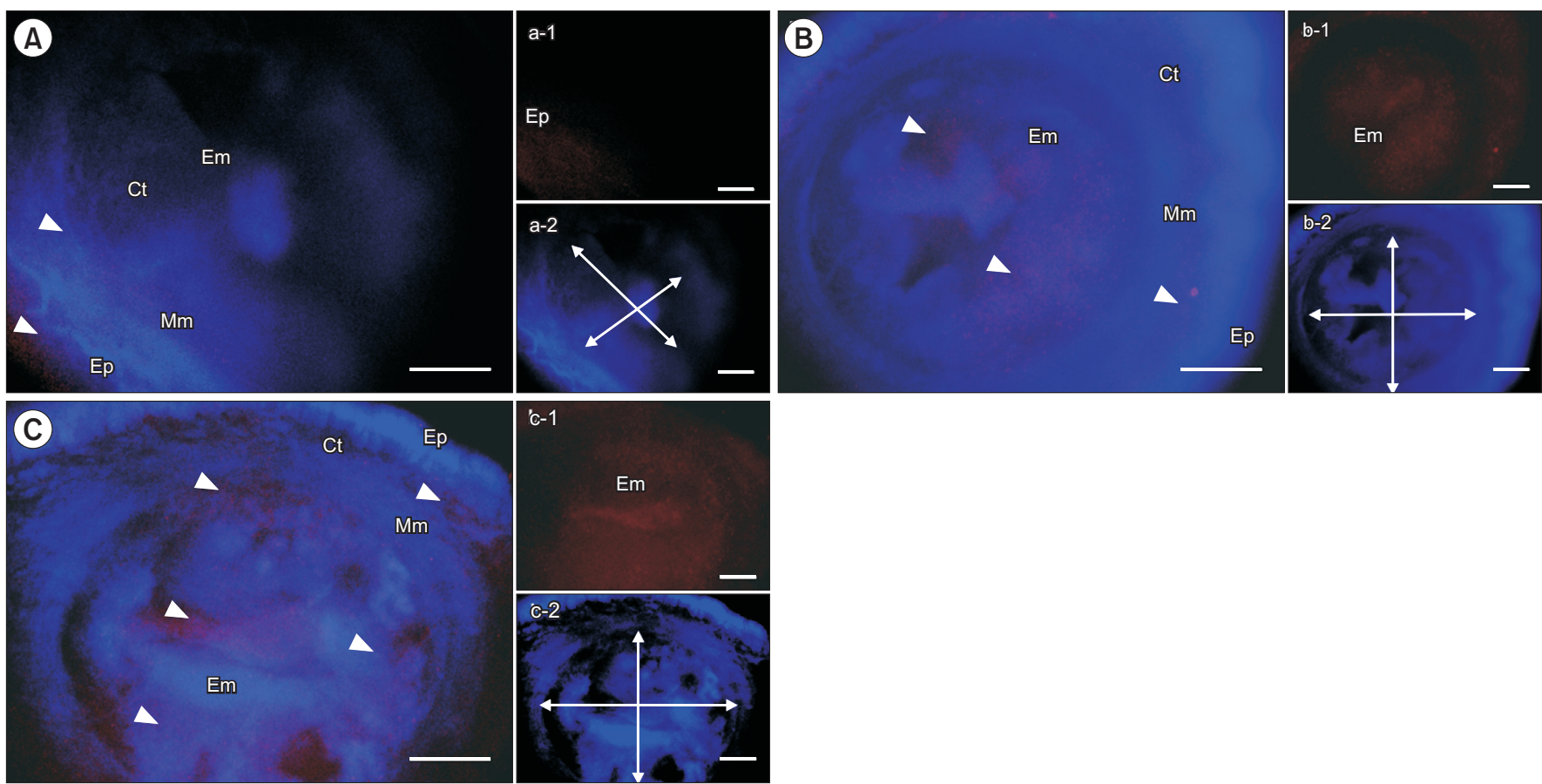

Fig. 3. Immunofluorescence analysis of uterus in each mouse group. (A) Normal of uterus, (B) Uterus of mouse injected with cancer cell-line, (C) Uterus of mouse injected with cancer cell-line and PMSG hormone, a-1-c-1: VEGF protein expression, a-2-c-2: DAPI staining. White arrows is indicate VEGF expression. Em, endometrium; Mm, myometrium; Ct, connective tissue; Ep, epithelial tissue of endometrium (bar $=100 \mathrm{um}$ ).

confirmed to maximize the damage to the uterus, which was the same as a study that showed that the occurrence of cancer cells in the ideal signaling process of hormones (Ferlay et al., 2015; Lin et al., 2017). In other words, the injection of mouse intraperitoneal cancer cells was confirmed to increase the metastasis rate to the endometrium and myometrium (Arnold et al., 2005). In other words, as colon cancer increases in the form of malignant cancer due to damage of the protooncogene, it increases the activity of VEGF, a neovascular factor, and regenerates blood vessels at the damaged site (Arnold et al 2005; Sillars-Hardebol et al., 2010; Jeong and Song, 2014). In addition, increase in VEGF is believed to serve as a biological marker in the event of cancer (Ferrara and DavisSmyth, 1997; Otrock et al., 2007; Roskoski, 2007). As shown in Roskoski's 2007 study, it was confirmed that the angiogenesis factor of endometrial subgroup increased significantly in the cancer-injected group. Especially, in the group treated with PMSG, the histological alteration of the endometrium and the glandular area, which is the main site of the endometrium, were very high and the VEGF activity was maximized (Biswas and Hyun, 2007; Contreras et al., 2010). In other words, the injection of colorectal cancer can be seen as a very rapid transfer of cancer to the mouse uterus, increasing the deformation of tissue in the inner membrane. This phenomenon is that the intraperitoneal injection of colorectal cancer cell line may be lower than the intrauterine injection of uterine cancer cells in the process of modeling endometrial cancer. However, it is believed to be a model for analyzing the metastases of multiple cancers as well as the endometrium cancer. In addition, the increase of PMSG as a data on hormonal imbalance can increase the amount of endothelial cancer, and is also considered to be of high research value as a major factor in increasing the activity of VEGF. Thus, the study can provide basic data on the transfer and generation of multiple cancers using colorectal cancer in the model of endometrial cancer, and may suggest that it is also relevant to PMSG, which plays a role in the development of endometrial and follicle.

\section{CONFLICTS OF INTEREST}

No potential conflict of interest relevant to this article was reported. 


\section{AUTHOR CONTRIBUTIONS}

Conceptualization; SH Kim, JT Yoon. Data curation: SH Kim. Formal analysis: SH Kim, NH Jung, MG Oh. Funding acquisition: JT Yoon. Investigation: SH Kim, MG Oh. Methodology: SH Kim, NH Jung, MG Oh. Project administration: SH Kim, JT Yoon. Resources: SH Kim, JT Yoon. Supervision: JT Yoon. Roles/Writing - original draft: SH Kim, NH Jung. Writing - review \& editing: SH Kim, JT Yoon.

\section{AUTHOR'S POSITION AND ORCID NO.}

\author{
SH Kim, Ph.D., \\ https://orcid.org/0000-0003-0996-6912 \\ NH Jung, Student, \\ https://orcid.org/0000-0003-3073-960X \\ MG Oh, Researcher, \\ https://orcid.org/0000-0002-9289-3779 \\ JT Yoon, Professor, \\ https://orcid.org/0000-0002-9408-8239
}

\section{REFERENCES}

Arnold CN, Goel A, Blum HE, Boland CR. 2005. Molecular pathogenesis of colorectal cancer: implications for molecular diagnosis. Cancer 104:2035-2047.

Biswas D and Hyun SH. 2007. Effect of vascular endothelial growth factor on porcine in vitro maturation. J. Embryo Transf. 22:213-218.

Cheung LW, Hennessy BT, Li J, Yu S, Myers AP, Djordjevic B, Lu Y, Stemke-Hale K, Dyer MD, Zhang F, Ju Z, Cantley LC, Scherer SE, Liang H, Lu KH, Broaddus RR, Mills GB. 2011. High frequency of PIK3R1 and PIK3R2 mutations in endometrial cancer elucidates a novel mechanism for regulation of PTEN protein stability. Cancer Discov. 1:170-185.

Contreras CM, Akbay EA, Gallardo TD, Haynie JM, Sharma S, Tagao O, Bardeesy N, Takahashi M, Settleman J, Wong KK, Castrillon DH. 2010. Lkbl inactivation is sufficient to drive endometrial cancers that are aggressive yet highly responsive to mTOR inhibitor monotherapy. Dis. Model. Mech. 3:181-193.

Ferlay J, Soerjomataram I, Dikshit R, Eser S, Mathers C, Rebelo M, Parkin DM, Forman D, Bray F. 2015. Cancer incidence and mortality worldwide: sources, methods and major patterns in GLOBOCAN 2012. Int. J. Cancer 136:E359-E386.

Ferrara N and Davis-Smyth T. 1997. The biology of vascular endothelial growth factor. Endocr. Rev. 18:4-25.

Glaab WE, Risinger JI, Umar A, Kunkel TA, Barrett JC, Tindall KR. 1998. Characterization of distinct human endometrial carcinoma cell lines deficient in mismatch repair that originated from a single tumor. J. Biol. Chem. 273:26662-26669.

Jeong W and Song G. 2014. EGF, IGF-I, VEGF and CSF2: effects on trophectoderm of porcine conceptus. Reprod. Dev. Biol. 38:21-34.

Jin DI and Yang MH. 1997. Effects of superovulation induction on embryo quantity and quality in rat. Korean J. Embryo Transf. 12:127-132.

Kim DS, Kim SH, Yoon JT. 2011. Expression of PAPP-A and $20 \alpha$-HSD in the bovine corpus luteum during early pregnancy. J. Embryo Transf. 26:57-63.

Kim KY and Choi KC. 2009. Gonadotropin-releasing hormone and its receptor as a therapeutic concept in the progression of epithelial ovarian cancer. J. Embryo Transf. 24:1-14.

Kim SH, Kim KL, Lee JH, Shin DH, Jung NH, Lee HJ, Yoon JT. 2018. Detection of matrix metalloproteinases patterns in bovine luteum cell during pregnancy. J. Embryo Transf. 33:6168.

Lee JY and Song G. 2013. The laying hen: an animal model for human ovarian cancer. Reprod. Dev. Biol. 37:41-49.

Lee M, Ahn JI, Kwun H, Ko DW, Ahn J, Lim JM. 2018. Possible improvement of oocyte supply by the use of aged mice and different gonadotrophins. J. Embryo Transf. 33:69-73.

Lin Q, Wang Y, Chen D, Sheng X, Liu J, Xiong H. 2017. Cisplatin regulates cell autophagy in endometrial cancer cells via the PI3K/AKT/mTOR signalling pathway. Oncol. Lett. 13:35673571.

Lionti S, Reggiani Bonetti L, Bettelli S, Spallanzani A, Gelsomino F, Barresi V. 2018. Histopathological variables in liver metastases of patients with stage IV colorectal cancer: potential prognostic relevance of poorly differentiated clusters. Hum. Pathol. 78:115-124.

McConechy MK, Ding J, Cheang MC, Wiegand K, Senz J, Tone A, Yang W, Prentice L, Tse K, Zeng T, McDonald H, Schmidt AP, Mutch DG, McAlpine JN, Hirst M, Shah SP, Lee CH, Goodfellow PJ, Gilks CB, Huntsman DG. 2012. Use of mutation profiles to refine the classification of endometrial carcinomas. J. Pathol. 228:20-30.

Morice P, Leary A, Creutzberg C, Abu-Rustum N, Darai E. 2016. Endometrial cancer. Lancet 387:1094-1108.

Otrock ZK, Makarem JA, Shamseddine AI. 2007. Vascular endothelial growth factor family of ligands and receptors: review. Blood Cells Mol. Dis. 38:258-268.

Park HY and Kang MJ. 2011. Regulation of long-chain Acyl-CoA synthetase 4 expression with progesterone and estradiol17ß. Reprod. Dev. Biol. 35:215-219.

Roskoski R Jr. 2007. Vascular endothelial growth factor (VEGF) signaling in tumor progression. Crit. Rev. Oncol. Hematol. 62:179-213.

Siegel RL, Miller KD, Fedewa SA, Ahnen DJ, Meester RGS, Barzi A, Jemal A. 2017. Colorectal cancer statistics, 2017. CA Cancer J. Clin. 67:177-193.

Siegel RL, Miller KD, Jemal A. 2015. Cancer statistics, 2015. CA Cancer J. Clin. 65:5-29.

Sillars-Hardebol AH, Carvalho B, de Wit M, Postma C, Delis- 
van Diemen PM, Mongera S, Ylstra B, van de Wiel MA, Meijer GA, Fijneman RJ. 2010. Identification of key genes for carcinogenic pathways associated with colorectal adenomato-carcinoma progression. Tumour Biol. 31:89-96.

Torre LA, Bray F, Siegel RL, Ferlay J, Lortet-Tieulent J, Jemal A. 2015. Global cancer statistics, 2012. CA Cancer J. Clin. 65:87108.

Weigelt B, Warne PH, Lambros MB, Reis-Filho JS, Downward
J. 2013. PI3K pathway dependencies in endometrioid endometrial cancer cell lines. Clin. Cancer Res. 19:3533-3544.

Yun SK, Yu WJ, Yun YW. 1998. Differential effects of gonadotropin-releasing hormone ( $\mathrm{GnRH})$ agonist on ovarian function in early and late follicular phase of pregnant mare serum gonadotropin (PMS G) -pretreated immature rats. Korean J. Embryo Transf. 13:261-275. 